http://jmscr.igmpublication.org/home/ ISSN (e)-2347-176x ISSN (p) 2455-0450 crossref DOI: https://dx.doi.org/10.18535/jmscr/v8i9.42

\title{
Management of Multiple Mucogingival Defects by way of Versatile Free Gingival Graft
}

Authors

\section{Dr Suchetha $A^{1}$, Dr Joseph Kishore Reddy ${ }^{2}$, Dr Darshan $\mathbf{B M}^{3}$, Dr Sapna $\mathbf{N}^{4}$, Dr Apoorva $\mathrm{SM}^{5}$, Dr Divya Bhat ${ }^{6}$, Dr Freeda Ampotti ${ }^{7}$}

${ }^{1}$ Professor and Head, Department of Periodontology, DAPMRV Dental College, Bangalore, Karnataka

${ }^{2,7}$ Post Graduate Student, Department of Periodontology, DAPMRV Dental College, Bangalore, Karnataka

${ }^{3,4,5}$ Reader, Department of Periodontology, DAPMRV Dental College, Bangalore, Karnataka

${ }^{6}$ Senior Lecturer, Department of Periodontology, DAPMRV Dental College, Bangalore, Karnataka

\begin{abstract}
Background: Gingival recession is defined as exposure of the root surface by an apical shift in the position of the gingiva. It is most probably the result of the cumulative effect of minor pathologic involvement like inflammation or repeated trauma to the gingiva. 2 The other etiologic factors are faulty tooth brushing technique (gingival abrasion), tooth malposition, friction from soft tissues (gingival ablation), abnormal frenum attachment. The treatment of gingival recession comes under mucogingival surgery. There are many treatment modalities are present to correct gingival recession defects. They are use of free gingival autograft, free connective tissue autograft, pedicle autografts, laterally (horizontally) positioned, Coronally positioned, Semilunar pedicle (Tarnow), Sub epithelial connective tissue graft (Langer), Guided tissue regeneration, Pouch and tunnel technique. Despite of the advances in technique of correction of gingival recession, free gingival graft continues to be a reliable procedure for increasing the width of keratinized gingiva and stopping the progression of gingival recession.

Case Presentation: In the present article discussing two case reports presented with millers class II GR with abnormal frenum pull. Classic technique given Bjorn by using free gingival graft was used.There was a significant reduction in RD after one month and 3months post operatively.

Conclusion: The free gingival graft for root coverage is a feasible and effective treatment procedure in mucogingival surgery. Despite the fact that other effective root coverage techniques have been described, the free gingival graft may still be the best treatment choice for gingival recession.
\end{abstract}

\section{Introduction}

Gingival recession is defined as exposure of the root surface by an apical shift in the position of the gingiva. It is most probably the result of the cumulative effect of minor pathologic involvement like inflammation or repeated trauma to the gingiva. ${ }^{2}$ The other etiologic factors are faulty tooth brushing technique (gingival abrasion), tooth malposition, friction from soft tissues (gingival ablation), abnormal frenum attachment. $^{3,4}$ The mechanism of gingival recession is due to localized inflammatory 
processes in the connective tissue with the accumulation of mononuclear cells as described by Baker and Seymour in 1976. In the initial stage there is normal or subclinical inflammation, there is proliferation of epithelial rete pegs resulting in loss of CT core and finally there is merging of oral and Sulcular epithelium resulting in separation and recession of the gingival tissues due to loss of nutritional supply. ${ }^{5}$ Waerhaug proposed that if the free gingiva is voluminous the infiltrate will occupy only a small portion of the connective tissue however, if it is thin the entire connective tissue portion may be involved consequently there is proliferation of epithelial cells from the oral and dentogingival epithelium. Thus the zone of CT decreases and it is obliterated by the fusion of these two epithelia. Finally, the epithelium loses its nutritional source, and it lead to gingival recession. ${ }^{6}$

According to Millers classification, Gingival recession is of 4 types and class II is the most prevalent among younger individuals which require esthetic concern. Millers Class II Marginal tissue recession that extends to or beyond the MGJ, with no periodontal loss in the interdental area; the tooth is well-aligned in the arch. Abnormal frenum pull is one of the common etiologic factor in the marginal gingival recession in anterior areas. If there is adequate gingiva coronal to the frenum, there is usually no need to surgically remove it. A frenum that encroaches on the margin of the gingiva may interfere with plaque removal and tension on this frenum may tend to open the sulcus. In these cases, surgical removal of the frenum is indicated.

The treatment of gingival recession comes under mucogingival surgery. There are many treatment modalities are present to correct gingival recession defects. They are use of free gingival autograft, free connective tissue autograft, pedicle autografts, laterally (horizontally) positioned, Coronally positioned, Semilunar pedicle (Tarnow), Sub epithelial connective tissue graft (Langer), Guided tissue regeneration, Pouch and tunnel technique. Despite of the advances in technique of correction of gingival recession, free gingival graft continues to be a reliable procedure for increasing the width of keratinized gingiva and stopping the progression of gingival recession. At present, even though the free gingival grafts is less predictable compared to subepithelial connective tissue grafts as far as root coverage is concerned, it is most commonly used procedure as being simple, multiple teeth can be treated at one time, easy tissue handling, and can be performed when keratinized gingiva adjacent to involved is insufficient. They were initially described by Bjorn' in 1963. It is called classic technique to increase the width of attached gingiva. The following variants to the classic technique are described in this section: accordion technique, strip technique, or a combination of both. All are modifications of the free grafts. In the present article discussing two case reports presented with millers class II GR with abnormal frenum pull.

\section{Case 1}

26 years old female patient visited our department with chief complaint of receding gums in the lower anterior region (See figure $1 \mathrm{~b}, 1 \mathrm{c}$ ). She had no previous history of orthodontic treatment. Oral hygiene was good and there was no bleeding on probing. On examination revealed recession depth (RD) of $5 \mathrm{~mm}$ and recession width (RW) of $2 \mathrm{~mm}$ was seen wrt 31.Clinically diagnosed as Millers class II gingival recession. Radiographic examination revealed no interproximal bone loss. Tension test shows positive wrt mandibular arch indicated abnormal frenum attachment.

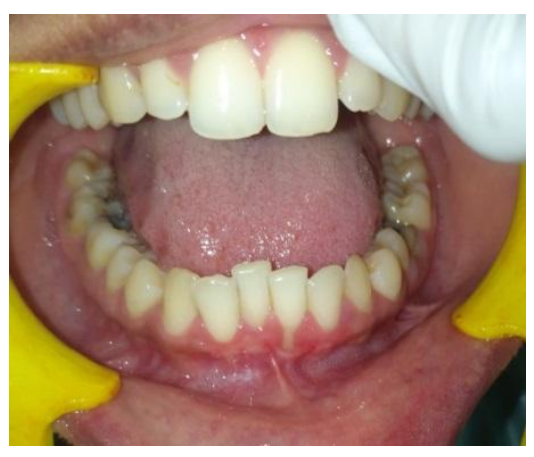

Fig 1a 


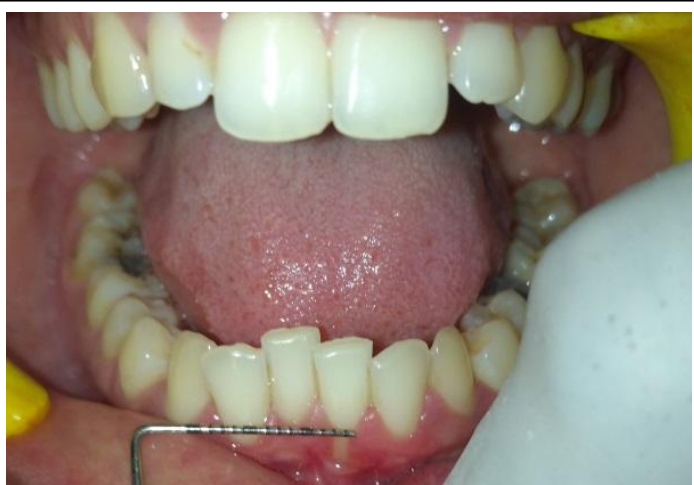

Fig 1b

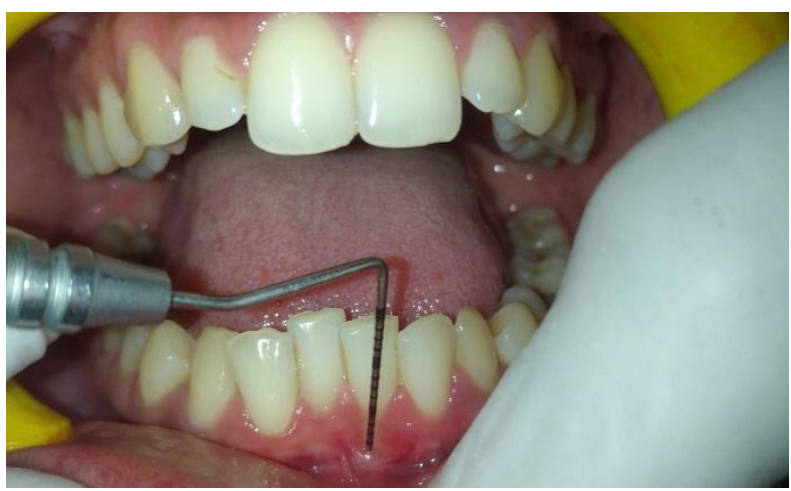

Fig 1c

\section{Case 2}

26 years old female patient visited our department with chief complaint of receding gums gin in lower anterior region (See figure 2a, 2b). She had no previous history of orthodontic treatment. Oral hygiene was good and there was no bleeding on probing. On examination revealed RD of $7 \mathrm{~mm}$ and RW of $3 \mathrm{~mm}$ was seen wrt 41.Clinically diagnosed as Milers class IIgingival recession. Radiographic examination revealed no interproximal bone loss. Tension test shows positive wrt mandibular arch indicated abnormal frenum attachment.

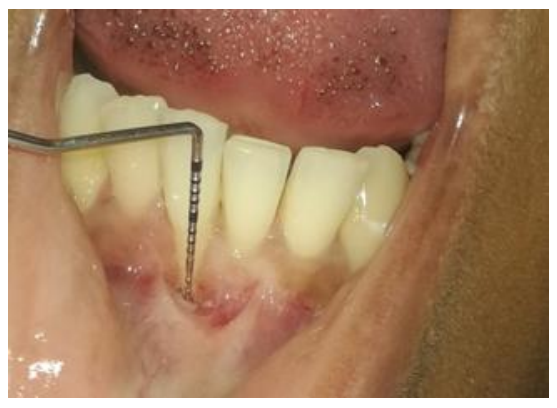

Fig 2a

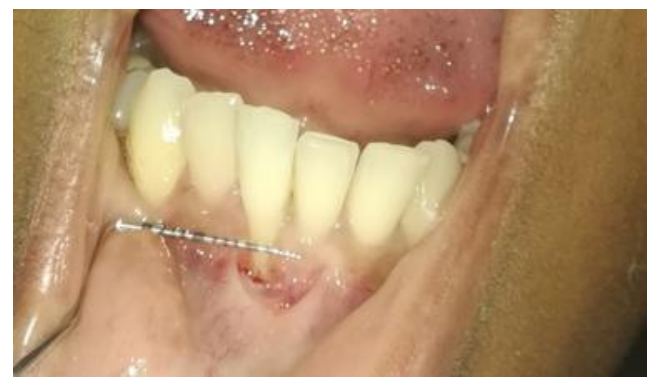

Fig 2b

\section{Case Management}

In the present case report, classic technique given Bjorn was used. Before the treatment, the treatment plan was thoroughly explained to the patient and a written consent was taken before initiation of the therapy. Phase 1 therapy of scaling and root planing was done prior to the surgery. Mandibular frenotomy was done. In the first step recipient Site was prepared. The purpose of this step is to prepare a firm connective tissue bed to receive the graft. In the second step graft was obtained from the donor site. Template was made over the donor site and shallow incision was given around it with a \#15 blade. (Fig 3a,3b, $4 a, 4 b)$. Blade was inserted to the desired thickness at one edge of the graft. Elevated the edge and holded it with tissue forceps to separate the graft, as separation progresses to provide visibility. The FGG was harvested from palate (Fig 4c). In the third step graft was transferred to the recipient site. The graft was adapted over the root and stabilized by horizontal and circumferential sutures using 4.0 vicryl sutures $(5 \mathrm{a}, 5 \mathrm{~b})$.A modified Hawleys appliance was given to patient to prevent patient discomfort and postoperative complications and assist in healing (Fig 6a, 6b).

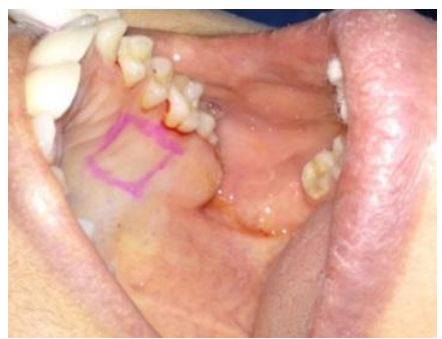

Figure 3a 


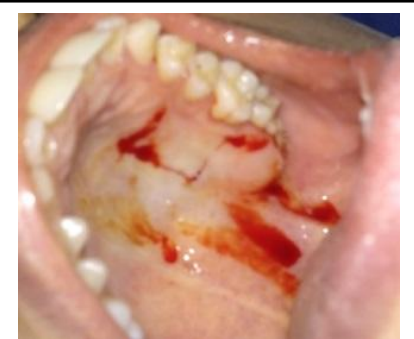

Fig 3b

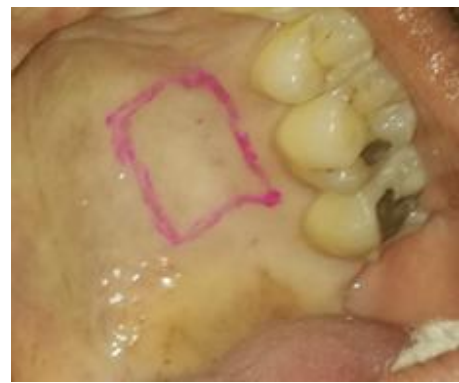

Fig 4a

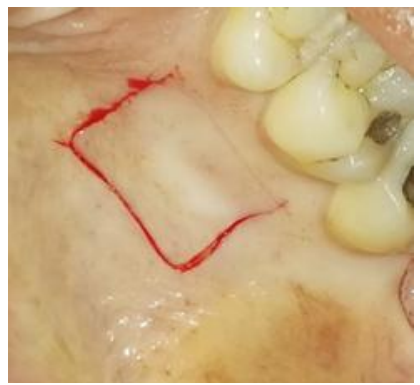

Fig 4b

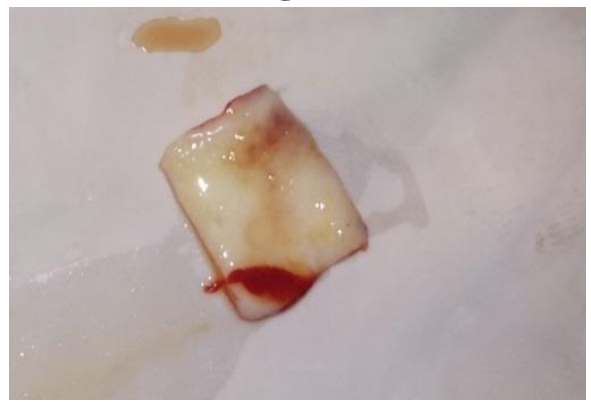

Fig 4c

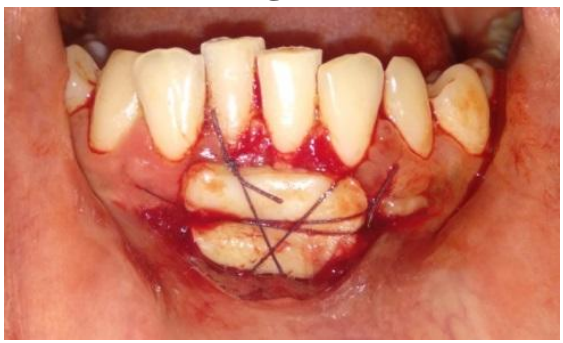

Fig 5a

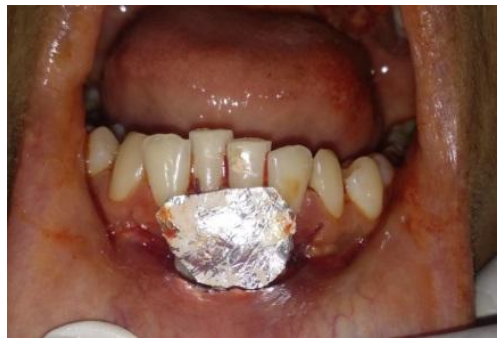

Fig 5b

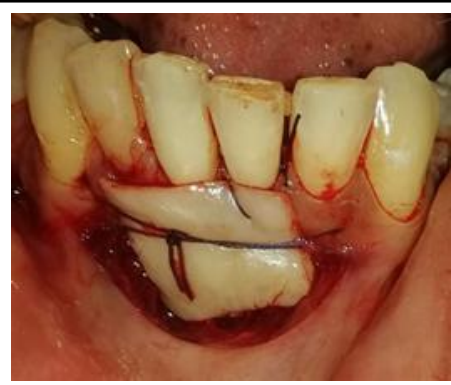

Fig 5c

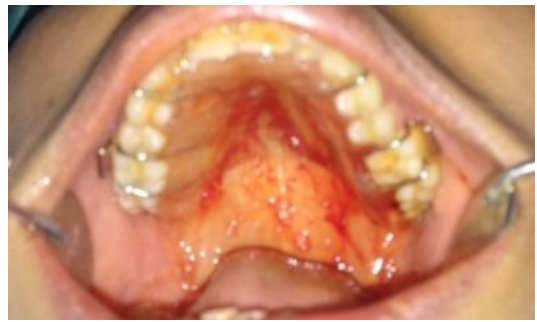

Fig 6a

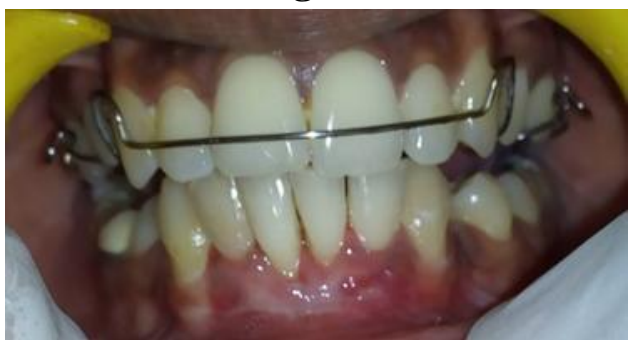

Fig 6b

\section{Outcome}

In case 1 , there was a significant reduction in RD from $5 \mathrm{~mm}$ to $1 \mathrm{mmand} \mathrm{RW}$ from $2 \mathrm{~mm}$ to 0 after one month and 3 months post operatively. There was a significant reduction in RD from $7 \mathrm{~mm}$ to $3 \mathrm{~mm}$ and $\mathrm{RW}$ from $3 \mathrm{~mm}$ to $1 \mathrm{~mm}$ after one month and 3 months post operatively.

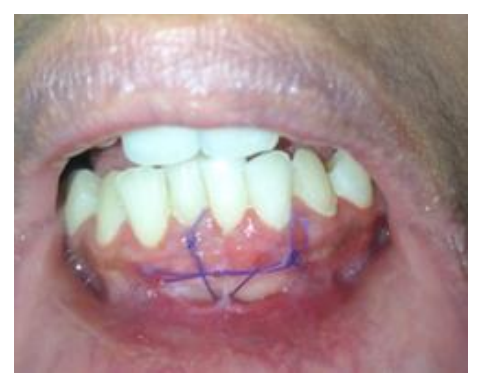

Fig $7 \mathbf{a}$

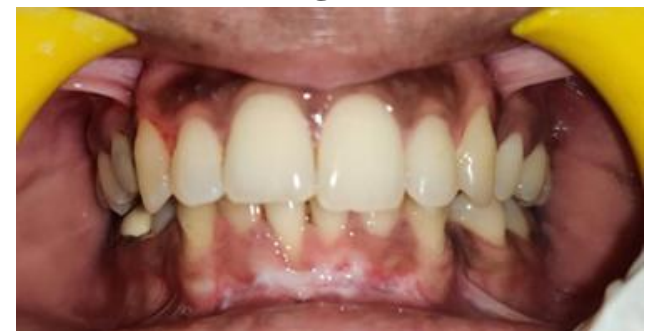

Fig $7 b$ 


\section{Discussion}

In the present case reports, it revealed abnormal frenal attachment is the cause for gingival recession. Stoner et al through his study mention that gingival recession had been caused by anatomical features of soft tissue eg. high frenum attachment associated with narrow band of attached gingiva which might cause excessive tension on the marginal tissue. Tissue phenotype is one of the critical factors influence recession. In general patients presented with either thick flat or thin scalloped phenotypes. A clinical study was done by Kan JU et al and reviewed that patients with thin gingival phenotype were more likely to experience gingival recession. Patients with thick and flat gingival phenotypes exhibit short papillae whereas thin and scalloped phenotypes represent long papillae. Thick phenotypes include flat soft tissue and bony architecture, denser and more fibrotic soft tissue with large amount of attached masticatory mucosa. It is more resistant to any acute trauma. ${ }^{14}$ In the present case reports patient presented with thin scalloped biotype and it may be one of the cause of gingival recession. The gingival thickness also affects the treatment outcome possibly because of the difference in the amount of blood supply to the underlying bone and susceptibility to resorption. Initial gingival thickness predicts the outcome of any root coverage procedures. ${ }^{15}$

Free gingival grafts are still commonly used to increase the width of attached gingiva. ${ }^{17}$ Bjorn in 1963, and Sullivan and Atkins in 1968, were the first to describe the free gingival graft. ${ }^{18,}$. The free gingival graft was initially used to increase the amount of attached gingiva and extend the vestibular depth. Later it was used to attempt coverage of exposed root surfaces. It is Simple and highly predictable when used to increase the amount of attached gingiva, it is also quite versatile: it can also be used over an extraction socket or osseous graft $^{20}$ One disadvantage of a free gingival graft is the different shade of the graft obtained from the donor palatal mucosa. The donor tissue may be more opaque, and thicker, which may lead to esthetic problems of varying severity, depending on the shade of the palate and gingiva, and may become worse by the formation of keloids. Wennström et al observed that the average percentage of root coverage was nearly $72 \%$ in the FGG studies. In our study average percentage of rot coverage was around $68.55 \%$. Blanes and Allen stated that the achievement of root coverage is possible in cases where the interproximal soft tissue integrity remained, as in the present case report there was no interproximal bone loss.

\section{Conclusion}

The free gingival graft for root coverage is a feasible and effective treatment procedure in mucogingival surgery. Despite the fact that other effective root coverage techniques have been described, the free gingival graft may still be the best treatment choice for gingival recession.

\section{References}

1. J. Sabarinathan Prevalence of Gingival Recession among the Different Races of Patients Reporting to Penang International Dental College, International Journal of Dental Sciences and Research, 2014, Vol. 2, No. 4A, 1-3.

2. Susin C, Haas AN, Oppermann RV, Haugejorden O, Albandar JM. Gingival recession: epidemiology and risk indicators in a representative urban Brazilian population. J Periodontol 2004;75(10):1377-86.

3. Hall WB. Present status of soft tissue grafting. J Periodontol 1977; 48:587-597

4. Breitenmoser, Mormann W, Muhlemann HR. Damaging effects of toothbrush bristle end form on gingiva. J Periodontol 1979; 50:212- 216.

5. Baker D.L., \& Seymour, D.J. The possible pathogenesis of gingival recession. A histological study of induced recession in the rat. J Clin Periodontol 1976; 3:208219. 
6. Waerhaug, J. The gingival pocket. Anatomy, pathology, deepening and elimination. Odontologisk Tidskrift 1952; 60, suppl.

7. American Academy of Periodontology: Proceedings of the World Workshop in Clinical Periodontics. Annals of Periodontology. Chicago, 1989, The Academy.

8. American Academy of Periodontology: Proceedings of the World Workshop in Periodontics. Annals of Periodontology. Chicago, 1996, The Academy.

9. Bowers, G.M. (1963). A study of the width of attached gingiva. Journal of Periodontology 34, 201-209.

10. Freedman, A.L., Green, K., Salkin, L.M., Stein, M.D. \& Mellado, J.R. (1999). An 18-year longitudinal study of untreated mucogingival defects. Journal of Periodontology 70, 1174-1176.

11. Ochsenbein, C. (1960). Newer concept of mucogingival surgery. Journal of Periodontology 31, 175-185.

12. Gottsegen, R. (1954). Frenulum position and vestibular depth in relation to gingival health. Oral Surgery 7, 1069-1078.

13. Vikas Jindal,Variations in the frenal morphology in the diverse population: A clinical study, Journal of indian society of periodontology. Vol 20,Issue 3,Page no 320-323.

14. Kan JY, Morimoto T, Rungcharassaeng K, Roe P, Smith DH Int J Periodontics Restorative Dent. 2010 Jun; 30(3):237-43.

15. Review Flap thickness as a predictor of root coverage: a systematic review. (Hwang D, Wang HLJ Periodontol. 2006 Oct; 77(10):1625-34.)

16. Philippe bouchard. Decision-making in aesthetics: root coverage revisited, Periodontology 2000, Vol. 27, 2001, 9712.
17. Barbosa FI, Corrêa DS, Zenóbio EG, Costa FO, Shibli JA. Dimensional changes between free gingival grafts fixed with ethyl cyanoacrylate and silk sutures. J Int Acad Periodontol. 2009;11 (2):170- 176.)

18. Bjorn H: Free transplantation of gingiva propia. Sveriges Tandlak T 1963; 22:684.

19. Sullivan HC, Atkins JC: Free autogenous gingival grafts. III. Utilization of grafts in the treatment of gingival recession. Periodontics 1968; 6:152.

20. Gudio G, Nieri M, Rotundo R, Cortellini $P$, Pini Prato G. Free gingival grafts to increase keratinized tissue: A retrospective long-term evaluation (10 to 25 years) of outcomes. J Periodontol 2008;79:587- 94. 